\title{
Conflito de atribuições no controle e fiscalização de alimentos de origem animal no Brasil, a luz da Constituição Federal
}

Conflict on control and inspection of foods from animal origin in Brazil, compared to the Constitution text.

Conflicto de competencias sobre el control y la inspección de los alimentos de origen animal en Brasil, frente a la Constitución

Francisco Pereira de Lacerda Filho'

RESUMO: O objetivo do estudo foi analisar o conflito de atribuições entre órgãos de vigilância sanitária e outros órgãos envolvidos na fiscalização e controle da produção de alimentos de origem animal no Brasil, a luz da Constituição Federal. Para tanto, foi realizado levantamento e análise jurídico-doutrinária dos dispositivos constitucionais que regulamentam a fiscalização e o controle de alimentos de origem animal. Também se avaliou, sob a perspectiva constitucional, as principais leis federais em vigor que tratam do assunto de forma a permitir uma melhor compreensão do assunto e solução do problema. O estudo evidenciou que existe conflito de atribuições entre órgãos do Poder Executivo no que diz respeito à fiscalização e controle da produção de alimentos de origem animal. Concluiu também que os normativos que amparavam a fiscalização desses produtos por parte dos órgãos do Ministério da Agricultura, Pecuária e Abastecimento não foram recepcionados pela Carta Magna, retirando tacitamente a atribuição para realizar estes serviços.

Palavras-chave: Vigilância Sanitária. Conflito de Atribuições. Controle de Produtos de Origem Animal.

ABSTRACT: The aim of the study was to analyze the conflict of responsibilities between health authorities and other agencies involved in monitoring and controlling the production of food of animal origin in Brazil, compared to the Constitution. It was conducted a survey a legal and doctrinal analysis of the constitutional provisions about the supervision and control of animal foods origin. Also evaluated under the constitutional perspective, the main federal laws in place that deal with the subject in order to allow a better understanding of the subject and problem solving. The study showed that there are conflicts of powers between the government and the agencies regarding the supervision and control of these products. It also concluded that the rules that sheltered the regulation of these products by the Ministry of Agriculture, Livestock and Supply were not expected by the Constitution Keywords: Health Surveillance. Assignment Conflict. Animal Products Control.

RESUMEN: El objetivo del estudio fue analizar el conflicto de competencias entre las autoridades de salud y otras instituciones que participan en la vigilancia y el control de la producción de alimentos de origen animal en Brasil, frente a la nueva Constitución Federal. Hizo los análisis jurídico y doctrinal de las disposiciones constitucionales sobre la

\footnotetext{
${ }^{1}$ Advogado. Especialista em Gestão do Trabalho e da Educação na Saúde (UFRN). Especialista em Direito Público e Penal (Processus Faculdade de Direito). Analista Técnico-Administrativo do Ministério da Saúde em Brasília - Distrito Federal. Brasil. E-mail: fplacerda1976@hotmail.com.
} 
supervisión y control de los alimentos de origen animal. También fue evaluado bajo la constitución y las principales leyes federales sobre esta tematica con el fin de mejor comprensión de la materia y la resolución de problemas. El estudio mostró que existe un conflicto de competencias entre los órganos del poder ejecutivo en materia de seguimiento y control de la producción de alimentos de origen animal. También concluyó que las normas que protegen la regulación de estos productos por los órganos del Ministerio de Agricultura, Ganadería y Abastecimiento, no fueron recibidas por la Constitución, que permite la revocación automática y la consiguiente falta de competencia para llevar a cabo estos servicios.

Palabras-Ilave: Vigilancia de la Salud. Conflicto de Asignación. Control de productos de origen animal.

\section{Introdução}

A Constituição Federal de 1988 foi promulgada com o objetivo de garantir os direitos sociais, econômicos, políticos e culturais que desde o regime militar (1964-1985) tinham sido suspensos. É a lei fundamental e suprema do Estado Brasileiro, pois traz a estruturação e organização de seus órgãos, contendo as normas fundamentais de Estado, e nisso se torna superior às demais normas, que somente serão válidas se guardarem conformidade com aquela.

A partir do surgimento dessa Carta Política o direito à saúde tornou-se universal e uma obrigação do Estado, conforme previsto em seu art. 196 (1):

Art. 196. A saúde é direito de todos e dever do Estado, garantido mediante políticas sociais e econômicas que visem à redução do risco de doença e de outros agravos e ao acesso universal e igualitário às ações e serviços para sua promoção, proteção e recuperação.

O Sistema Único de Saúde - SUS foi criado para efetivar esse direito, tendo priorizado as atividades de prevenção, aí incluídas as ações e serviços de vigilância sanitária com princípios e diretrizes garantidoras e protetores.

O controle e a fiscalização de alimentos, procedimentos, produtos e substâncias de interesse para a saúde foi atribuído ao SUS, conforme preconizado no art. 200, I e VI, do texto constitucional (1):

Art. 200 Ao sistema único de saúde compete, além de outras atribuições, nos termos da lei:

I - controlar e fiscalizar procedimentos, produtos e substâncias de interesse para a saúde e participar da produção de medicamentos, equipamentos, imunobiológicos, hemoderivados e outros insumos;

$[\ldots]$

VI - fiscalizar e inspecionar alimentos, compreendido o controle de seu teor nutricional, bem como bebidas e águas para consumo humano. 
A regulamentação desses dispositivos se deu por meio da Lei n. 8.080, de 19 de setembro de $1990^{2}$ (2), que atribui ao SUS, dentre outras competências, a de fiscalizar e inspecionar alimentos, água e bebidas para consumo humano, conforme previsão no art. $6^{0}$, VIII.

Nos termos desta Lei, vigilância sanitária pode ser entendida como:

Art. $6^{\circ}, \S 1^{\circ}$ entende-se por vigilância sanitária um conjunto de ações capaz de eliminar, diminuir ou prevenir riscos à saúde e de intervir nos problemas sanitários decorrentes do meio ambiente, da produção e circulação de bens e da prestação de serviços de interesse da saúde.

De forma semelhante, a Lei n. 9.782/99, de 26 de janeiro de 1999 (3), que define o Sistema Nacional de Vigilância Sanitária, cria a Agência Nacional de Vigilância Sanitária e dá outras providências, em seu art. $8^{\circ}, \S 1^{\circ}$, II, afirma ser competência da Agência Nacional de Vigilância Sanitária (ANVISA), "a regulamentação, o controle e a fiscalização de alimentos para consumo humano, desde sua produção até o consumo".

Por outro lado, a Lei n. 1.283, de 18 de dezembro de 1950 (4), que dispõe sobre a inspeção industrial e sanitária dos produtos de origem animal, a exemplo de carnes, mel, ovos e leite atribui aos órgãos do Ministério da Agricultura, Pecuária e Abastecimento (MAPA) a competência fiscalizatória sobre esses produtos enquanto localizados nas indústrias, fábricas, usinas, nas propriedades rurais e nos estabelecimentos entrepostos ${ }^{3}$.

Em 24 de novembro de 1989, foi publicada a Lei n. 7.889 (5), que estabeleceu a competência da União (Ministério da Agricultura), dos Estados (Secretarias de Agricultura dos Estados, do Distrito Federal e dos Territórios), do Distrito Federal e dos Municípios (Secretarias ou Departamentos de Agricultura dos Municípios), para a realização da inspeção sanitária e industrial dos produtos de origem animal, deixando a cargo dos órgãos de saúde pública a fiscalização nas casas atacadistas e nos estabelecimentos varejistas, conforme previsão em seu art. $3^{\circ}$, alínea "g" e art. $4^{\circ}$, alínea "d", assim exposto:

Art. 3ํㅗ A fiscalização, de que trata esta lei, far-se-á:

[...]

g) nas casas atacadistas e nos estabelecimentos varegistas.

\footnotetext{
2 A Lei n. 8080/90, dispõe sobre as condições para a promoção, proteção e recuperação da saúde, a organização e o funcionamento do SUS é conhecida como Lei Orgânica da Saúde (LOS).

3 Entrepostos são locais de armazenamento, acondicionamento, fracionamento, recebimento e distribuição de produtos, sem criação ou abate de animais. Não se confundem com casas atacadistas, pois estas não dispõem de qualquer manipulação ou fracionamento e somente realizam distribuição e comércio por atacado.
} 
Art. 4ํ São competentes para realizar a fiscalização de que trata esta Lei: (Redação dada pela Lei no 7.889, de 1989).

a) o Ministério da Agricultura, nos estabelecimentos mencionados nas alíneas a, b, c, d, e, e f, do art. 3oㅡ que façam comércio interestadual ou internacional; (Redação dada pela Lei no 7.889, de 1989).

b) as Secretarias de Agricultura dos Estados, do Distrito Federal e dos Territórios, nos estabelecimentos de que trata a alínea anterior que trata a alínea anterior que façam comércio intermunicipal; (Redação dada pela Lei № 7.889, de 1989).

c) as Secretarias ou Departamentos de Agricultura dos Municípios, nos estabelecimentos de que trata a alínea a desde artigo que façam apenas comércio municipal; (Redação dada pela Lei no 7.889, de 1989)

d) os órgãos de saúde pública dos Estados, do Distrito Federal e dos Territórios, nos estabelecimentos de que trata a alínea $\mathrm{g}$ do mesmo art. 3‥ (Incluído pela Lei no 7.889, de 1989)

Ainda nesse conjunto de legislação que envolve o assunto, existe o Decreto-Lei $n$. 986, de 21 de outubro de 1969 (6), que institui normas básicas sobre alimentos, tendo estabelecido que:

Art. 29. A ação fiscalizadora será exercida:

I - Pela autoridade federal, no caso de alimento em trânsito de uma para outra unidade federativa e no caso de alimento exportado ou importado;

II - Pela autoridade estadual ou municipal, dos Territórios ou do Distrito Federal nos casos de alimentos produzidos ou expostos à venda na área da respectiva jurisdição.

Diversos problemas surgiram diante desse confronto de normas, especialmente a duplicidade de fiscalização para fins sanitários e a errônea aplicação da legislação, constantes embates políticos nos diversos níveis de governo, sendo necessário enfrentar o conflito de normas por meio de um estudo aprofundado da constitucionalidade da legislação que trata do assunto, levando em conta o princípio da supremacia constitucional, o fenômeno da recepção e o conflito de leis no tempo.

Nesse contexto, a pesquisa buscou esclarecer dúvidas geradas a respeito da atribuição legal para fiscalizar e inspecionar estabelecimentos produtores de alimentos de origem animal, bem como para realizar o controle de tais produtos no comércio atacadista e varejista frente ao quantitativo de normas existentes antes e após a nova Constituição Federal. 


\section{Metodologia}

Tratou-se de um estudo bibliográfico e doutrinário a respeito do conflito de atribuições institucionais entre os órgãos de Vigilância Sanitária e outros órgãos envolvidos na fiscalização e controle da produção de alimentos de origem animal no Brasil sob o contexto da atual Constituição Federal Brasileira.

Teve como unidade de pesquisa a legislação federal vigente comparando com as atribuições do SUS criadas no art. 200 da Constituição Federal de 1988, bem como o entendimento doutrinário acerca do assunto.

Para compreender as atribuições constitucionais sobre fiscalização e controle de alimentos de origem animal e possíveis conflitos institucionais entre órgãos, buscou-se 0 entendimento doutrinário em livros acadêmicos, artigos, teses e sítios eletrônicos.

O levantamento de leis se deu por meio de pesquisa legislativa e suas regulamentações no sítio eletrônico da Presidência da República ${ }^{4}$ e teve como parâmetro de busca as palavras: 'fiscalização e inspeção de produtos de origem animal', 'sistema único de saúde' e 'conflito de competências'.

\section{Resultados e Discussão}

A partir do método de pesquisa aplicado foi encontrada a legislação pertinente ao tema abordado, tendo-se identificado que a norma mais antiga por que deveria começar o estudo é a Lei n. 1.283, de 18 de dezembro de 1950, que dispõe sobre a inspeção industrial e sanitária dos produtos de origem animal.

As análises de pesquisas indicam que boa parte da legislação referente à fiscalização e controle de alimentos de origem animal no Brasil, foi produzida em data anterior à promulgação da Constituição Federal de 1988 e com isso merece apreciação de sua aplicabilidade a fim de apreciar a sua recepção ${ }^{5}$ e com isso por fim ao conflito de normas instalado desde a Constituição.

Já os resultados da pesquisa doutrinária a respeito do tema demostraram que se faz necessária uma abordagem da legislação de fiscalização e controle de alimentos sob o enfoque constitucional, levando em conta o princípio da supremacia constitucional, o

\footnotetext{
${ }^{4}$ Este site disponibiliza para acesso público toda a legislação atualizada do país e está disponível em: http://www4.planalto.gov.br/legislacao.

5 Para o professor Michel Temer "A constituição nova recebe a ordem normativa que surgiu sob o império de Constituições anteriores se com ela for compatível". A esse fenômeno se deu o nome de Recepção.
} 
fenômeno da recepção das normas, sua constitucionalidade, bem como o conflito de leis no tempo.

Segundo José Cretella Júnior (7): "[...] no Brasil, o conflito de jurisdição ou de competência somente poderá ocorrer entre autoridades judiciárias. O conflito de atribuições, entre autoridades judiciárias e administrativas; ou entre autoridades administrativas".

Acrescentou ainda que (7):

[...] o conflito de atribuição, no Brasil, é, dentro de cada um dos Poderes, o choque entre duas autoridades, em matéria administrativa, decorrente do fato de ambas entenderem que são competentes ou incompetentes para o desempenho de determinada atividade que nada tem de jurisdicional ou de legislativa.

Assim, o conflito entre autoridades pode ser entendido como o conflito de atribuições e ocorre quando duas ou mais autoridades (administrativas ou judiciárias) praticam atos (não jurisdicionais) e colidentes entre si.

Uma mesma classe de atos pode ser praticada por mais de um órgão, desde que sucessivamente. Se, porém, dois órgãos diversos praticam os mesmos atos simultaneamente, entre eles se estabelece um conflito.

Por outro lado, toda lei tem sua validade em determinado espaço e tempo, permanecendo vigente até que outra a revogue. Neste processo de sucessão de normas surgem os conflitos de atribuições entre órgãos/entidades na aplicação do Direito.

Segundo Régis (8):

[...] O conflito de leis, decorrente da coexistência de duas normas distintas regulando uma mesma relação jurídica, surge a partir do momento em que são violados os limites temporais ou espaciais de aplicação de determinados preceitos jurídicos. [...] O conflito de leis no tempo é objeto de estudo do direito intertemporal, conceituado como o ramo da ciência jurídica que tenta responder às questões mais frequentes que envolvem a entrada em vigor de uma nova lei e o regramento das relações jurídicas pretéritas.

Delduque (9), bem esclareceu os parâmetros de solução deste fenômeno ao mencionar que:

Em caso de conflito entre duas regras que garantam direitos, ocorre o tudo ou o nada, ou seja, uma regra será sempre declarada inválida para que a outra possa triunfar. Para isso, utilizam-se critérios definidos pela doutrina, quais sejam: hierárquicos (uma lei superior invalida uma lei inferior); cronológicos (uma lei editada posteriormente revoga uma lei anteriormente 
editada) ou de especialidade (uma lei especial torna inválida uma lei de caráter geral).

Segundo Diniz (10), a Lei de Introdução às Normas do Direito Brasileiro (Decreto-Lei n. 4.657, de 04 de setembro de 1942) é um "conjunto de normas sobre normas, norma de sobre direito ou de apoio, consistente num conjunto de normas cujo objetivo é disciplinar as próprias normas jurídicas".

O citado Decreto-Lei (11) em seu art. 2o regulamenta as regras do direito intertemporal ao mencionar que "Não se destinando à vigência temporária, a lei terá vigor até que outra a modifique ou revogue", e complementa: "A lei posterior revoga a anterior quando expressamente o declare, quando seja com ela incompatível ou quando regule inteiramente a matéria de que tratava a lei anterior".

Essas regras são conhecidas como o princípio da continuidade das leis, em que uma norma terá vigor até que outra a modifique ou revogue. Assim, só uma lei pode revogar ${ }^{6}$ outra lei. Esta não pode ser revogada por decisão judicial ou por ato do Poder Executivo.

Em regra, as leis têm efeito permanente, isto é, uma vigência por prazo indeterminado, salvo quanto às leis de vigência temporária. A não aplicação da lei não implica na renúncia do Estado em atribuir-lhe efeito. Portanto, o fato de as inspeções e fiscalização de alimentos de origem animal serem feitas nas indústrias ou nas propriedades rurais por órgãos do Ministério da Agricultura, Secretarias de Agricultura dos Estados ou dos Municípios não invalida a competência dos órgãos da vigilância sanitária pela mesma fiscalização, já que prevista constitucionalmente e na Lei Orgânica da Saúde.

Assim, em que pese os órgãos do Ministério da Agricultura se utilizarem da Lei $n$. 1.283/50 para fundamentar suas inspeções e fiscalização sobre produtos de origem animal, a mesma já não se encontra em vigor, e isso se dá pelo fato de, além de não ter sido recepcionada pela Constituição Federal de 1988, a Lei n. 1.283/50 já havia sido revogada pelo Decreto-Lei 986, de 21 de outubro de 1969, que determinou que a fiscalização de alimentos recaia sobre os órgãos da saúde, conforme previsão em seu art. 29, I e II.

\footnotetext{
${ }^{6}$ A revogação é a perda total de vigência de uma lei ou de um determinado dispositivo legal. Pode ser dividida em: ab-rogação: ocorre com a perda total de sua vigência; derrogação: ocorre com a perda de alguns artigos da lei; expressa: a própria lei dispõe sobre a revogação, e tácita: ocorre quando há incompatibilidade entre a lei nova e a lei velha ou quando a lei nova regula inteiramente um assunto disposto na lei velha. Nos dois casos, revogam-se as leis velhas.
} 
Ao enfrentar o conflito de atribuições existentes entre órgãos da vigilância sanitária e órgãos do Ministério da Agricultura, Dias (12) deixa claro que:

[...] a atual organização administrativa brasileira sobre fiscalização de alimentos no Brasil é complexa e há órgãos e entidades atuando sobre o mesmo assunto nas pastas da saúde e da agricultura, o que ocasiona conflitos de interesses e fragilidades na atividade de prevenção e proteção à saúde.

O citado autor (12) acrescentou ainda que: "[...] urge que se ponha fim a tais desencontros finalísticos das duas Pastas, compatibilizando-se as normas infraconstitucionais, eliminando-se de vez os conflitos existentes, evitando-se perplexidades que o direito repele".

Carvalho (13) destaca que "desde a edição do Decreto-Lei n. 986/69, já poderia ter deixado de aplicar o dispositivo da Lei n.1.283/50 que dá competência ao Ministério da Agricultura, quanto à fiscalização de alimentos". Acrescentou ainda que "a fiscalização realizada pelos órgãos da agricultura além de não possuírem fundamento na Constituição, vão de encontro ao seu art. 196, ocasionando graves prejuízos institucionais à prevenção da saúde".

Igual posicionamento é adotado por Costa (14) ao mencionar que:

[...] a repartição de atribuições entre os setores da saúde e da agricultura nunca foi ponto pacífico, manifestando-se que a legislação, muitas vezes, tem apresentado lacunas, ambiguidades e conflitos de atribuições, inclusive a legislação atual.

Acrescentou ainda que essas questões requerem estudos institucionais que identifiquem e expliquem os "acordos" no Estado para a partilha do poder político na questão do controle sanitário no campo dos alimentos, cuja regulamentação manifestará no discurso normativo outras ambiguidades, conflitos de competências e contradições.

Assim, mesmo para aqueles que entendam que a Lei n. 7.889/89, tenha restabelecido a competência dos órgãos da agricultura para a realização da inspeção sanitária e industrial dos produtos de origem animal, ainda assim the falta competência constitucional. Isso porque a citada lei foi editada, posteriormente à Constituição Federal de 1988, sem levar em conta os dispositivos do art. 200, VI, que menciona ser atribuição o 
SUS e não aos órgãos do Ministério da Agricultura para fiscalizar e inspecionar alimentos, estando, portanto, eivada de inconstitucionalidade por ação7.

Para o constitucionalista José Afonso da Silva (15): "todas as normas que integram a ordenação jurídica nacional só serão válidas se se conformarem com as normas da Constituição Federal". Acrescentou ainda que:

[...] a constituição federal é a lei suprema do Estado, pois é nela que se encontram a própria estruturação deste e a organização de seus órgãos; é nela que se acham as normas fundamentais de Estado, e só nisso se notará sua superioridade em relação às demais normas jurídicas.

O citado autor (15), traduzindo o pensamento de Kelsen, conclui que:

[...] constituição é, então, considerada norma pura, puro dever ser, sem qualquer pretensão a fundamentação sociológica, política ou filosófica. A concepção de Kelsen toma a palavra Constituição em dois sentidos: no lógico-jurídico e no jurídico-positivo. De acordo com o primeiro, Constituição significa norma fundamental hipotética, cuja função é servir de fundamento lógico transcendental da validade da Constituição jurídico-positiva, que equivale à norma positiva suprema, conjunto de normas que regula a criação de outras normas, lei nacional no seu mais alto grau.

Gilmar Mendes (16) entende que a norma fundamental é aquela que "numa determinada comunidade política unifica e confere validade às suas normas jurídicas, as quais, em razão e a partir dela, se organizam e/ou se estruturam em sistema”.

Daí se entende pela competência do SUS para o controle e fiscalização de alimentos de origem animal, pois o mandamento constitucional deixa claro que essas ações encontram-se inseridos dentro das atribuições dos órgãos de vigilância sanitária, conforme disposto na Carta Maior e regulamentado na Lei Orgânica da Saúde.

Assim, ao visualizar-se o ordenamento jurídico como uma estrutura hierarquizada de normas de maneira a conformar um sistema, o chamado sistema jurídico, torna-se nítido o conceito de supremacia da Constituição, de forma que todos os normativos (a exemplo das Leis n. 1.283/1950 e 7.889/1989) devem estar em consonância com a mesma. E neste ponto é importante notar a inconstitucionalidade da Lei n. 7.889/89.

Por outro lado, cabe mencionar a não recepção da Lei n. 1.283/50, já que a nova ordem constitucional atribuiu competência de controle, fiscalização e inspeção de

7 Segundo o autor José Afonso da Silva, a Constituição Federal de 1988 reconhece duas formas de inconstitucionalidades: por ação e por omissão. A inconstitucionalidade por ação ocorre com a produção de atos legislativos ou administrativos que contrariem normas ou princípios da constituição. Já a inconstitucionalidade por omissão verifica-se nos casos em que não sejam praticados atos legislativos ou administrativos requeridos para tornar plenamente aplicáveis normas constitucionais. 
alimentos de origem animal aos órgãos de proteção à saúde, restando prejudicado o exercício dessas ações por parte dos órgãos da agricultura. E cabe ressaltar que o mandamento constitucional é condição de validade aos demais diplomas legais, de tal sorte que, quando uma norma se encontra em oposição à Carta Maior, não existe outra alternativa senão afastá-la deste ordenamento, a exemplo desta lei da década de 50.

O Supremo Tribunal Federal $(\mathrm{STF})^{8}$ possui 0 poder de decidir sobre a constitucionalidade das normas jurídicas que foram aprovadas antes e depois da entrada em vigor da Constituição de 1988.

O controle de constitucionalidade caracteriza-se, em princípio, como um mecanismo de correção presente em determinado ordenamento jurídico, consistindo em um sistema de verificação da conformidade de um normativo em relação à Constituição, conforme entendimento de Gilmar Mendes (16). O citado autor acrescentou ainda que: "o controle de constitucionalidade no Brasil pode ser caracterizado pela originalidade e diversidade de instrumentos processuais destinados à fiscalização da constitucionalidade dos atos do poder público e à proteção dos direitos fundamentais".

Esse controle jurisdicional também conhecido como controle jurídico ou judiciário é o controle de constitucionalidade exercido pelos órgãos do Poder Judiciário, conforme salienta José Afonso da Silva(15):

O controle jurisdicional, generalizado hoje em dia, denominado judicial review nos Estados Unidos da América do Norte, é a faculdade de que as constituições outorgam ao Poder Judiciário de declarar a inconstitucionalidade de lei e de outros atos do Poder Público que contrariem, formal ou materialmente, preceitos ou princípios constitucionais.

O controle de constitucionalidade de norma pré-constitucional frente à constituição atual é feito por meio do controle concentrado de constitucionalidade. A Constituição de 1988 (art. 102, $1^{\circ}{ }^{\circ}$ ) previu o instrumento da arguição de descumprimento de preceito fundamental (ADPF) que, em acordo ao disposto na Lei n. 9.882/99 (17) que a regulamenta, permite que o controle recaia sobre atos normativos editados anteriormente à atual Carta Magna, a teor do art. 1ำ, parágrafo único, I:

Art. $1^{\circ} \mathrm{A}$ arguição prevista no $\S 1^{\circ}$ do art. 102 da Constituição Federal será proposta perante o Supremo Tribunal Federal, e terá por objeto evitar ou reparar lesão a preceito fundamental, resultante de ato do Poder Público.

\footnotetext{
${ }^{8}$ O Supremo Tribunal Federal é a suprema corte judicial do Brasil e guardião da Constituição Federal.
} 
Parágrafo único. Caberá também arguição de descumprimento de preceito fundamental:

I - quando for relevante o fundamento da controvérsia constitucional sobre lei ou ato normativo federal, estadual ou municipal, incluídos os anteriores à Constituição.

$[\ldots]$

Para Gilmar Mendes (16):

[...] é pressuposto para o ajuizamento da Arguição de Descumprimento de Preceito Fundamental a existência de controvérsia judicial ou jurídica relativa à constitucionalidade da lei ou à legitimidade do ato questionado. Caberá também a arguição de descumprimento quando for relevante o fundamento da controvérsia constitucional sobre lei ou ato normativo federal, estadual ou municipal, inclusive anteriores à Constituição (leis préconstitucionais).

Assim, fica claro que as ações dos órgãos de fiscalização do Ministério da Agricultura, fundamentadas nas Leis n. 1.283/1950 e 7.889/1989, concernente ao controle e à fiscalização dos produtos de origem animal não possuem o respaldo constitucional, não tendo sido recepcionada a primeira norma, devendo ser atacada por meio de ADPF e a segunda norma se encontra eivada de vícios de inconstitucionalidade, pois não observou as atribuições dos órgãos da saúde, previstas no art. 200 da Carta Maior.

Portanto, aos órgãos do Ministério da Agricultura falta atribuição legal para realizar fiscalização em produtos de origem animal, e isso ocasiona graves riscos à saúde humana, conforme entendimento de Costa (14):

[...] Na realidade, a maior parte dos municípios brasileiros não inspeciona os produtos de origem animal, nem dispõe de condições adequadas de abate. Em muitos casos, esses locais se transformam em sérios problemas de saúde pública. Diferentemente da atuação do setor saúde o Ministério da Agricultura tem seus serviços instalados nos próprios estabelecimentos, desenvolvendo uma ação de inspeção dos animais a serem abatidos, carnes, leite etc, que, a rigor, deveria ser de responsabilidade do produtor, cabendo ao Estado a atividade de fiscalização que incluiria inspeção.

Acrescentou ainda que (14):

[...] Questões dessa natureza são frequentes no campo da Vigilância Sanitária e muitas vezes chegam a obstruir ou retardar medidas de proteção da saúde em situações críticas, como ocorreu na tragédia com a cachaça contendo metanol em anos recentes no Estado da Bahia.

Os órgãos do Ministério da Agricultura ainda permanecem realizando essas inspeções nos produtos de origem animal, o que tem ocasionado sérios embates institucionais e consequentes prejuízos à saúde pública, conforme concluiu Costa (14). A 
fiscalização desses produtos pelos órgãos da agricultura se mostra frágeis, visto a pouca cobertura nesses serviços no território brasileiro. Acrescentou também que a falta de fiscalização pelos órgãos da saúde se deve ao fato de o SUS ainda não estar totalmente implementado, precisando de melhor efetivação quanto às ações fiscalizatórias por parte da vigilância sanitária.

Em outra vertente, o cidadão tem direito à proteção a sua saúde por meio de ações prestacionais do Estado instrumentalizadas pela vigilância sanitária. Conforme entendimento de Delduque (9) "pode-se afirmar que a atividade conhecida como vigilância sanitária é um instrumento de garantia da dimensão da proteção à saúde".

Segundo Lucchese (18):

[...] nas relações de produção-consumo, fica bem claro que, uma das principais funções do Estado democrático moderno é a de promover e proteger a saúde e o bem-estar dos cidadãos, intervindo nas atividades das empresas, disciplinando-as, quando põe em risco a saúde pública.

Acrescentou ainda que uma plena estruturação da Vigilância Sanitária é requisito fundamental para a implantação do SUS, principalmente em função do seu poder de regulação e fiscalização dos serviços contratados, bem como controlar a qualidade dos insumos terapêuticos consumidos por esses serviços. Para este autor (18) "existe um grande potencial de contribuição à ruptura e superação do antigo padrão de ação governamental no campo da saúde, acusado de ineficiente, perdulário e fraudulento".

\section{Considerações Finais}

A análise da legislação sob o enfoque constitucional, levando em conta preceitos doutrinários e hermenêuticos permite concluir que os órgãos do Ministério da Agricultura não possuem atribuição legal para realizar fiscalização em produtos de origem animal, e isso ocasiona graves riscos à saúde humana, visto que a União, Estados e Municípios não inspecionam esses produtos nem dispõe de condições adequadas para efetivação desses serviços.

Com o advento da nova Constituição Federal de 1988, a vigilância sanitária ganhou previsão constitucional, possuindo a atribuição primária na inspeção e fiscalização de alimentos de origem animal, disso decorrendo a não recepção da Lei n. 1.283/50, bem como a inconstitucionalidade da Lei n. $7.889 / 89$, já que define essa atribuição a outros órgãos não integrantes do SUS. 
Neste contexto, cabe ressaltar a legitimidade ativa do Ministério Público, com sua atribuição de 'custus legis', que Ihe confere a responsabilidade da fiscalização e correta aplicação das leis, o qual seria um dos legitimados para impetrar Ação Direta de Inconstitucionalidade em face da Lei n. 7.889/89 e Arguição de Descumprimento de Preceito Fundamental quanto à Lei n.1.283/50, conforme previsto no art. 103, caput, da Constituição Federal e art. $2^{\circ}$, I da Lei n. 9.882/99, de acordo com a abordagem realizada por Pereira (19) em seu artigo.

Diante de todas essas questões levantadas, torna-se necessário resgatar os ideais de construção do SUS, implementar políticas de fiscalização e inspeção em alimentos pelos órgãos da saúde e principalmente o empoderamento dessas ações frente ao poder econômico.

Tecido tais esclarecimentos a respeito da previsão constitucional dada aos órgãos do SUS no que tange à fiscalização e inspeção de alimentos, conclui-se que o controle e a fiscalização realizada pelos órgãos do Ministério da Agricultura, Pecuária e Abastecimento (MAPA) se torna contrário aos mandamentos da Constituição Federal, já que quando esta entrou em vigor, não recepcionou o ordenamento jurídico que se mostre com ela incompatível.

\section{Referências}

1 Brasil. Constituição da República Federativa do Brasil, 5 outubro de 1988. Brasília. [Acesso em 30 ago 2015]. Disponível em: http://www.planalto.gov.br/ccivil 03/Constituicao/Constituicao.htm

2 Brasil. Lei n. 8.080, de 19 de setembro de 1990. Dispõe sobre as condições para a promoção, proteção e recuperação da saúde, a organização e o funcionamento dos serviços correspondentes e dá outras providências. Diário Oficial da República Federativa do Brasil. Brasília, 20 de set 1990. [Acesso em 30 ago 2015]. Disponível em: http://www.planalto.gov.br/ccivil 03/Leis/L8080.htm

3 Brasil. Lei n. 9.782, de 26 de janeiro de 1999. Define o Sistema Nacional de Vigilância Sanitária, cria a Agência Nacional de Vigilância Sanitária, e dá outras providências. Diário Oficial da República Federativa do Brasil. Brasília, 27 de jan 1999. [Acesso em 20 out 2015]. Disponível em: http://www.planalto.gov.br/ccivil 03/leis/L9782.htm

4 Brasil. Lei n. 1.283, de 18 de dezembro de 1950. Dispõe sobre a inspeção sanitária e industrial dos produtos de origem animal, e dá outras providências. Diário Oficial dos 
Estados Unidos do Brasil. Rio de Janeiro, 19 de dezembro de 1950. [Acesso em 30 ago 2015]. Disponível em: http://www.planalto.gov.br/ccivil 03/Leis/L1283.htm

5 Brasil. Lei n. 7.889, de 23 de novembro de 1989. Dispõe sobre a inspeção sanitária e industrial dos produtos de origem animal. Diário Oficial da República Federativa do Brasil. Brasília, 24 de nov 1989. [Acesso em 30 ago 2015]. Disponível em: http://www.planalto.gov.br/ccivil 03/Leis/L7889.htm

6 Brasil. Decreto-Lei 986, de 21 de outubro de 1969. Institui normas básicas sobre alimentos. Diário Oficial da República Federativa do Brasil. Brasília, 22 de out 1969. [Acesso em 30 ago. 2015]. Disponível em: http://www.planalto.gov.br/ccivil 03/DecretoLei/Del0986.htm

7 Júnior JC. Do Conflito de Atribuição no Código de Processo Civil Brasileiro. Revista da Faculdade de Direito da Universidade de São Paulo 76(1):145-161, 1981 [Acesso em 10 nov 2015]. Disponível em: http://www.revistas.usp.br/rfdusp/article/viewFile/66919/69529

8 Régis MLD. O Direito Intertemporal e o Código Civil. São Paulo: Ed. Saraiva; 2004.

9 Delduque MC. Controle Judicial da Política Pública de Vigilância Sanitária: a Proteção da Saúde no Judiciário. [Tese]. São Paulo: Programa de pós-graduação stricto sensu em Saúde Pública da Universidade de São Paulo; 2010. [Acesso em 22 de set 2015]. Disponível em: http://www.teses.usp.br/teses/disponiveis/6/6135/tde-08122010-140717/ptbr.php

10 Diniz MH. Curso de Direito Civil Brasileiro. 26ae ed. Vol. I. São Paulo: Saraiva; 2009.

11 Brasil. Decreto-Lei n. 4.657, de 04 de setembro de 1942. Lei de Introdução às normas do Direito Brasileiro. Diário Oficial da República Federativa do Brasil. Rio de Janeiro, 09 de set 1942. [Acesso em 20 out 2015]. Disponível em:

http://www.planalto.gov.br/ccivil 03/decreto-lei/Del4657compilado.htm

12 Dias HP. Direitos e Obrigações em Saúde. Brasília: Agência Nacional de Vigilância Sanitária; 2002.

13 Carvalho PB. Conflito de Competências na Fiscalização de Alimentos de Origem Animal no Brasil: Uma Análise da Legislação em Vigor no Brasil. Revista de Direito Sanitário 5(1):18-39, 2004 [Acesso em 20 set 2015]. Disponível em: http://www.revistas.usp.br/rdisan/article/view/80885

14 Costa EA. Vigilância Sanitária e Proteção da Saúde. Biblioteca Virtual em Saúde-Ministério da Saúde 1(1):179-206, 2003 [Acesso em 20 set 2015]. Disponível em: http://gesan.ndsr.org/docmanualespecializacao11 VigilanciaSanitariaeprotecaodasaude.pdf.

15 Silva JA. Curso de direito constitucional positivo, 38ª ed. São Paulo: Malheiros; 2015.

16 Mendes GF. Curso de Direito Constitucional, 4ª ed. São Paulo: Saraiva; 2009. 
17 Brasil. Lei n. 9.882, de 03 de dezembro de 1999. Dispõe sobre o processo e julgamento da arguição de descumprimento de preceito fundamental, nos termos do $\S 1^{\circ}$ do art. 102 da Constituição Federal. Diário Oficial da República Federativa do Brasil. Brasília, 04 de dez de 1999. [Acesso em 20 out 2015]. Disponível em: http://www.planalto.gov.br/ccivil 03/leis/l9882.htm

18 Lucchese G. Globalização e regulação sanitária: os rumos da vigilância sanitária no Brasil. [Tese Doutorado em Saúde Pública]. Rio de Janeiro: Programa de pós-graduação stricto sensu em Saúde Pública da Escola Nacional de Saúde Pública da Fundação Oswaldo Cruz; 2001. [Acesso em 22 out 2015]. Disponível em: http://portalteses.icict.fiocruz.br/pdf/FIOCRUZ/2001/lucchgd/capa.pdf.

19 Pereira GD, Moura LA. Conflito de competências entre os Ministérios da Saúde e da Agricultura na fiscalização de produtos alimentícios no Brasil. Revista Eletrônica Tempus Actas de Saúde Coletiva 7(01):197-210, 2013 [acesso em 21 de nov. 2015]. Disponível em: http://www.tempusactas.unb.br/index.php/tempus/article/view/1287

\section{Como citar este artigo:}

Filho Lacerda FP. Conflito de atribuições no controle e fiscalização de alimentos de origem animal no Brasil, a luz da Constituição Federal. Revista Cadernos Ibero-Americanos de Direito Sanitário. 2016 out./dez, $5(4): 27-41$. 